\title{
Basal mechanics of Ice Stream B, West Antarctica 2. Undrained plastic bed model
}

\author{
Slawek Tulaczyk, ' W. Barclay Kamb, and Hermann F. Engelhardt \\ Division of Geological and Planetary Sciences, California Instıtute of Technology, Pasadena, Calıfornia
}

\begin{abstract}
Based on the results of our studies of the physical conditions beneath Ice Stream B, we formulate a new analytical ice stream model, the undrained plastic bed model (henceforth the UPB model). Mathematically, the UPB model is represented by a non-linear system of four coupled equations which express the relationships among ice sliding velocity, till strength, water storage in till, and basal melt rate. We examine this system of equations for conditions of ice stream stability over short timescales that permit holding ice stream geometry constant (less than hundreds of years). Temporal variability is introduced into the UPB model only by the direct dependence of till void ratio changes $(\dot{e}=\partial e / \partial t)$ on the basal melting rate $m_{r}$. Since till strength $\tau_{b}\{e\}$ and ice stream velocity $U_{b}\left\{\tau_{\mathrm{b}}\right\}$ change as long as till void ratio varies, the first condition for ice stream stability is that of constant till water storage $\dot{e}=0$. The second condition for ice stream stability arises from the feedback between ice stream velocity, till strength, and the basal melting rate which depends on shear heating $m_{r}\left\{U_{b} \tau_{b}\right\}$. This is the "weak till" condition which requires that in a steady state till strength is a small fraction of the gravitational driving stress $\tau_{b}<(n+1)^{-1} \tau_{d}$. The salient feature of the UPB model is its ability to produce two thermo mechanically controlled equilibrium states, one with a strong bed and slow ice velocities ("ice sheet" mode) and one with a weak bed and fast ice velocities ("ice-stream" mode). This bimodality of basal conditions is consistent with the available observations of subglacial conditions beneath slow and fast moving ice in West Antarctica. Basal conditions that do not correspond to these two steady states may occur transiently during switches between the two stable modes. The UPB model demonstrates that ice streams may be prone to thermally triggered instabilities, during which small perturbations in the basal thermal energy balance grow, leading to generation or elimination of the basal conditions which cause ice streaming.
\end{abstract}

\section{Introduction}

Studies of modern West Antarctic ice streams show that fast ice streaming is caused by an efficient basal lubricant, a weak basal till [Alley et al., 1986, 1987a, b; Blankenship et al., 1986, 1987; Engelhardt and Kamb, 1997; Engelhardt et al., 1990; $K a m b, 1991]$. Because of this weakness of the bed a significant part of the gravitational driving stress appears to be borne by ice stream margins [Echelmeyer et al., 1994; Jackson and Kamb, 1997; Raymond, 1996; van der Veen and Whillans, 1996; Whillans and van der Veen, 1997]. The Pleistocene geologic record also suggests that ice streaming took place predominantly where lubrication by weak till was available [Alley and MacAyeal, 1994; Clark, 1992; Marshall et al., 1996]. Thus the temporal and spatial patterns of slow (sheet like) and fast (stream like) ice motion are governed by the subglacial ice-till-water system, which couples geological, glaciological, and hydrological factors and processes. Recent advances have contributed significantly to our understanding of this complex system [Alley et al., 1986; 1987a, b, 1989; Anandakrishnan and Bentley, 1993; Blankenship et al., 1986, 1987; Boulton, 1996; Clark and Walder, 1994; Clarke,

\footnotetext{
Tow at Department of Geological Sciences, University of Kentucky, Lexington.

Copyright 2000 by the American Geophysical Unıon.

Paper number I999JB900328

0[48-0227/00/1999JB900328\$09.00
}

1987; Echelmever et al., 1994; Jackson and Kamb, 1997; Kamb, 1991; MacAyeal, 1992; Raymond, 1996; Walder and Fowler, 1994]. Despite these exciting developments, several fundamental questions remain: (1) what factors decide where and when basal lubrication and associated ice streaming appear?, (2) once active, how fast and in what fashion do ice streams evolve?, and (3) what processes bring an end to ice stream activity? The physics which govern this complex ice stream system need to be resolved and included in a realistic ice stream model which can be used for reliable predictions of ice stream and ice sheet behavior. The need for such reliable predictions is quite clear. Fast moving ice streams have a primary control over the mass balance of the West Antarctic Ice Sheet, whose stability needs to be investigated because of the existing concerns that discharge from this ice sheet could rise global sea level in the near future [Bentley, 1987, 1997; Bindschadler, 1997]. Ice streams are also presumed to have caused significant fluctuations in volume and extent of the Pleistocene ice sheets [e.g., Alley, 1991; Clark, 1992]. Moreover, ice sheets affected by large ice streams may have provided a pacemaker for regional/global climatic changes [Hughes, 1996; MacAyeal, 1993a, b].

In this paper we propose a new ice stream model. The model builds on the results of borehole and laboratory investigations of the physical conditions beneath Ice Stream B near the Upstream B camp (henceforth referred to as the UpB camp) [Engelhardt et al., 1990; Engelhardt and Kamb, 1993, 1997, 1998; Kamb, 1991; Kamb and Engelhardt, 1991; Tulaczyk, 1998; Tulaczyk et al., 1998; Tulaczyk et al., this issue]. This new model encapsulates 
relatively complex interactions between subglacial processes in a small number of equations and reveals the conditions for ice stream stability and evolution.

\section{Feedback Between Water Storage in Till and Basal Melting}

It has been long recognized that the subglacial lubrication that enables the fast motion of the West Antarctic ice stream is in some fashion related to the very low subglacial effective stresses [Alley et al., 1987a, 1989; Engelhardt et al., 1990; Engelhardt and Kamb, 1997]. Because of its dependence on effective stress, ice stream stability and evolution must be determined by the interplay between hydrologic and mechanical processes in the subglacial environment [e.g., Kamb, 1991]. In the first section of this paper we develop a new model of sub-ice stream hydrology which incorporates a negative feedback that arises from an interdependence between the basal melt rate, basal effective stress, till water content, and till strength. The distinguishing characteristic of this hydrologic model is the inclusion of water storage in till as the most important term. This storage-dominated hydrologic model is coupled later into an ice flow model to arrive at conditions for ice stream stability.

Our experimental work on water content and strength of the UpB till has shown that these till properties are very sensitively dependent on effective stress [Tulaczyk et al., this issue]. Therefore no significant changes in subglacial effective stress may take place without corresponding significant changes in till strength and void ratio. This observation has led us to the conclusion that a realistic model of sub-ice stream hydrology must include (1) water storage in till pore spaces and (2) the dependence of melt rate on effective stress (through the dependence of shear heating on the till strength). The effective stress dependence of basal melting can be made clear by noticing that shear heating is one of the major controls on the magnitude of the basal melt rate. For an ice base at the pressure melting point, this rate is determined by balance of thermal energy with two energy sources, shear heating and geothermal flux, and one energy sink, conductive heat loss, thus [Lingle and Brown, 1987, equation (10)]:

$$
m_{r}=\frac{\tau_{b} U_{b}+G-k_{i} \Theta_{b}}{L_{l} \rho_{l c e}},
$$

where $\tau_{b}$ is the basal shear stress, $U_{b}$ is the velocity of basal sliding, $G$ is the geothermal flux, $k_{t}=2.1 \mathrm{~W} \mathrm{~m}^{-1}{ }^{\circ} \mathrm{C}^{-1}$ is the thermal conductivity of ice, $\Theta_{b}$ is the temperature gradient at the base of the ice, $L_{t}=333.5 \mathrm{~kJ} \mathrm{~kg}^{-1}$ is the latent heat of fusion and $\rho_{\text {cee }} \approx$ $900 \mathrm{~kg} \mathrm{~m}^{-3}$ is the ice density. If $m_{r}$ is less than zero, (1) gives the rate of basal freeze-on. For an ice stream whose motion is accommodated by the deformation of till of plastic rheology, the magnitude of the basal shear stress is equal to the plastic strength of the till, or $\tau_{b}=\tau_{f}$. At this point the dependence of the basal melt rate on effective stress becomes apparent because the till strength is a linear function of effective stress [Tulaczyk et al., this issue].

We will illustrate our storage-dominated model of sub-ice stream hydrology using the bed of Ice Stream B at the UpB camp as an example. Thanks to intensive geophysical and borehole investigations, subglacial physical conditions are well known in this area [e.g., Alley et al., 1986; Blankenship et al., 1986, 1987; Engelhardt and Kamb, 1997; Engelhardt et al., 1990; Kamb, 1991; Tulaczyk et al., 1998]. First, we will establish the appropriate values for the variables in (1) to estimate the sign and mag- nitude of basal melting in the UpB area. The conductive heat loss can be determined using borehole measurements that show a basal temperature gradient equal to $\sim 0.041{ }^{\circ} \mathrm{C} \mathrm{m}^{-1}$ [Engelhardt and Kamb, 1993]. The shear heating term in equation (1) can be also constrained quite well because from laboratory measurements we know that $\tau_{f}$ is equal to $2 \pm 0.5 \mathrm{kPa}$ [Kamb, 1991]. Given this low basal stress, internal deformation of ice does not contribute significantly to ice stream velocity, and the observed ice stream velocity of $440 \mathrm{~m} \mathrm{yr}^{-1}$ [Whillans and van der Veen, 1993] can be attributed fully to basal sliding and till deformation [Engelhardt and Kamb, 1998]. Unfortunately, the geothermal tlux has not been determined by direct observations in the area of interest. Rose [1979] used temperature measurements in the Byrd station borehole located several hundred kilometers to the east and north of the UpB area to infer that the geothermal flux is equal to $\sim 0.06 \mathrm{~W} \mathrm{~m}^{-2}$.

Figure 1 illustrates a range of values of the basal melt rate for geothermal fluxes between 0.05 and $0.08 \mathrm{~W} \mathrm{~m}^{-2}$, which are reasonable bounds [Turcotte and Schubert, 1982, Table 4-1]. The first-order observation that can be made is that both basal melting and freezing are possible beneath Ice Stream B, depending on the exact value of the geothenmal flux and shear heating. Let us first consider the case that there is generation of basal meltwater at the base of Ice Stream B. We propose that this water may be either drained away through some form of a basal water system or it Inay be incorporated into the structure of the shearing till. The focus here will be on water storage in till because this process was previously neglected but, as will be shown later, may be of fundamental importance to understanding ice stream motion. Our experience with remolding till in the laboratory in the presence of free water indicates that deformation of till permits free water to be incorporated into till pore spaces. As a result of such remolding, till increases its void ratio. Since there are theoretical and observational reasons to believe that the till beneath Ice Stream B experiences some deformation at least near its top [Engelhardt and Kamb, 1998; Tulaczyk, 1998], we hypothesize that any meltwater generated at the base of this ice stream and not drained away is incorporated into the underlying till. Thus the rate of change of till void ratio in a sub-ice stream water system with storage can be expressed as a function of the difference between the basal melt rate $m$, and the drainage rate $d_{r}$ :

$$
\frac{\partial e}{\partial t} \equiv \dot{e}=\frac{m_{r}-d_{r}}{Z_{s}},
$$

where $e=V_{11} / V_{s}$ is the till void ratio (defined as the ratio of pore volume $V_{n}$ to the volume of till solids $\left.V_{s}\right), t$ is the time variable,

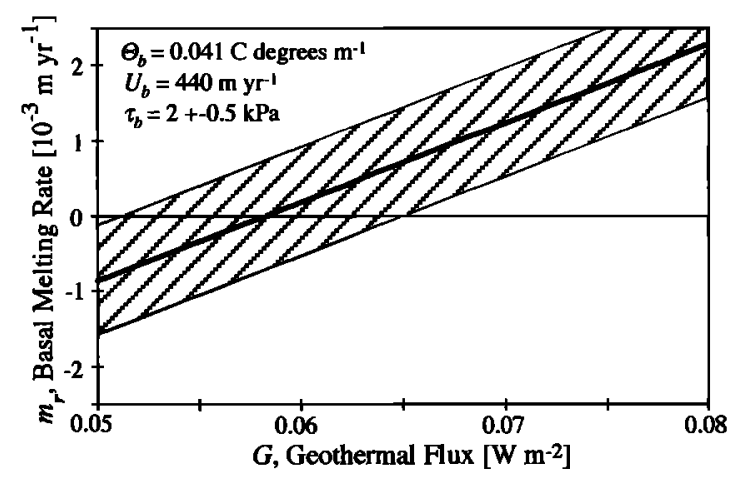

Figure 1. Dependence of the basal melt rate beneath Ice Stream $B$ (at the UpB camp) on the geothernal flux (equation (1)). 
and $Z_{s}$ is the thickness of till solids contained in the "active" till layer. Use of $Z_{s}$ instead of the overall thickness of the active till is more convenient when void ratio is the dependent variable. By the active till layer we mean that part of the subglacial till which undergoes deformation continuously or frequently. The physical controls on the depth of till deformation in the case of tili of plastic rheology were discussed in Tulaczyk [1999] and Tulaczyk et al. [this issue]. Since our model of sub-ice stream hydrology is focused on examining the effects of water storage in till pore spaces, we will treat the drainage rate $d_{r}$ as a constant whose value depends on the efficiency of the basal drainage system that is not explicitly treated here. This approach is justified as long as the drainage rate itself is independent of till void ratio.

With the exception of Darcian groundwater flow, none of the drainage mechanisıns proposed previously for sub-ice stream conditions contains any dependence of drainage efficiency on void ratio [Alley et al., 1989; Walder and Fowler, 1994; Weertman and Birchfield, 1982]. Calculations of Lingle and Brown [1987] and Tulaczyk [1998, chapter 5] indicate that long-distance meltwater drainage by way of Darcian groundwater flow beneath Ice Stream B is negligible because of low permeability of subglacial materials and low regional pressure gradients. However, we cannot rule out the possibility that a more complex system of short-distance groundwater drainage coupled with a network of Walder and Fowler canals, or some other form of a distributed sub-ice-stream drainage system [e.g., Hooke and Pohjola, 1994], could exhibit a significant dependence of drainage rate on void ratio. Pending further observational work on the physics of subice stream drainage [Engelhardt and Kamb, 1997], we limit ourselves here to considering the simple case of void ratioindependent drainage rate.

It is clear that in the system defined by (2) the till void ratio will increase as long as the difference between melt rate and the drainage rate is positive. However, the melt rate depends in an indirect way on till void ratio because the latter is related to the till strength. Typically, the strength of granular media is expressed as a function of effective stress rather than till void ratio. However, in shearing soils the three variables, strength, effective stress, and void ratio, are interrelated [Schofield and Wroth, 1968, p. 19]. This is because the effective stress controls both soil volume and strength [e.g., Tulaczyk et al., this issue, equations (1) and (2)]:

$$
\begin{gathered}
\tau_{f}=\sigma_{n}^{\prime} \tan \phi, \\
e=e_{o}-C \log \left(\sigma_{n}^{\prime} / \sigma_{n o}^{\prime}\right)=e_{o}-C \frac{\ln \left(\sigma_{n}^{\prime} / \sigma_{n o}^{\prime}\right)}{\ln (10)},
\end{gathered}
$$

where $\phi$ is the internal friction angle $\left(\sim 24^{\circ}\right.$ for the $U \mathrm{pB}$ till $), e_{\mathrm{o}}$ is the void ratio at the reference value of effective normal stress, $\sigma_{n o}^{\prime}=1 \mathrm{kPa}$, and $C$ is the dimensionless coefficient of compressibility. Equations ( $3 a$ ) and ( $3 b$ ) demonstrate that the state of a till whose water content is being increased by remolding, in this case shearing, in the presence of free water will migrate towards lower effective stresses and lower till strengths [e.g., Clarke, 1987, Tulaczyk et al., this issue]. By combining equations (3a) and (3b) one can eliminate $\sigma_{n}^{\prime}$ and express the till strength directly as a function of till void ratio:

$$
\tau,=\sigma_{n o}^{\prime} \tan (\phi) 10^{-\left(\left(e-e_{o}\right) / /\right)} \cong \sigma_{n o}^{\prime} \tan (\phi) \exp ^{-23\left(\left(e-e_{o}\right) / C\right)} .
$$

Subsequently, we will use the exponential form of (3c) for mathematical convenience. By fitting our laboratory data from torvane, shear box, and triaxial tests on samples of the UpB till (Figure 2), we can obtain an empirical analog of (3c):

$$
\tau_{f}=a \exp ^{-(b e)}=944,000 \exp ^{-(2) 7 e)}
$$

where $a=944,000 \mathrm{kPa}$ and $b=21.7$ are empirical constants, $\tau_{f}$ is in kilopascals and $e$ is expressed as a decimal fraction. In the broader context of ice stream mechanics, variations in till strength, and thus the basal stress, will require that the shear stress concentrated along the shear margins of the ice stream will vary in the opposite direction to maintain a constant driving stress. This aspect of our model will be explicitly treated in the next section.

To verify how sensitive the basal melt rate $m_{r}$ is to changes in till void ratio and strength, we substitute (3d) for $\tau_{b}$ in (1) and evaluate the new expression using the same values of independent variables as in Figure $I$ and assuming the geothermal flux inferred by Rose [1979], $G=0.06 \mathrm{~W} \mathrm{~m}^{-2}$. Figure 3 shows that the melt rate is very sensitive to till void ratio. For instance, at $e$ equal to 0.58 and till strength of $\sim 3.5 \mathrm{kPa}$, the melt rate is $\sim 2 \times$ $10^{-3} \mathrm{~m} \mathrm{y}^{-1}$, but an increase in till void ratio by only $3 \%$ brings the till strength down to $\sim 2.0 \mathrm{kPa}$ and the melt rate to near zero. Thus, as long as the rate of water storage is positive, $\left(m_{r}-d_{l}\right)>0$, the basal melt rate itself will decrease with time due to the negative feedback described by (1), (2), and (3d). This decrease will continue until the till strength, and thus the shear heating term in (1) adjust themselves to make the basal melt rate equal to the drainage rate $m_{r}=d_{r}$, and no more water is being stored in the till. A characteristic timescale $t_{c}$ for this process can be estimated from an integral of (2):

$$
t_{c} \sim \Delta e Z_{s} /\left(m_{r}-d_{r}\right),
$$

where $\Delta e$ is the required change in void ratio over the time $t_{c}$. Given reasonable values of $\Delta e \sim 10^{-2}, Z_{s} \sim 1 \mathrm{~m}$, and $\left(m_{r}-d_{r}\right) \sim$ $10^{-3} \mathrm{~m} \mathrm{yr}^{-1}$, the characteristic timescale is of the order of 10 years.

If we consider a case opposite to the one discussed above, meaning that the initial rate of water storage in till is negative $\left(m_{r}\right.$ $-d_{r}$ ) $<0$, a reverse negative feedback effect may force the till to lose water, strengthen, and increase shear heating to drive an increase in the basal melt rate towards the condition $m_{r}=d_{r}$. In reality a negative value of $\left(m_{r}-d_{1}\right)$ may occur either when the basal melt rate is positive but smaller than the drainage rate or when the basal melt rate is negative and basal freeze-on occurs. In the latter case it is reasonable to assume that the drainage rate would be zero under conditions of basal freezing. Among other things, a basal water film or shallow basal canals [c.g., Alley et al., 1989; Walder and Fowler, 1994] would be then susceptible to blockage by the accreting ice. Basal water deficit represented by either $m_{r}<d_{r}>0$ or $m_{r}<d_{r}=0$ will cause withdrawal of water from till, that is, till will consolidate. This must be associated with an increase in subglacial effective stress and till strength (equations (3a), (3b), and (3c)).

Here we will concentrate on analyzing qualitatively the case of till consolidation driven by freeze-on $\left(m_{r}<d_{r}=0\right)$ because the physics of this process are less obvious than that of the alternative case $\left(m_{r}<d_{r}>0\right)$. We want to verify whether it is physically feasible that a freeze-on driven consolidation of till will decrease till void ratio and increase till strength. In turn, stronger till may cause increased shear heating and increased shear heating may diminish the magnitude of basal freeze-on. One could argue that freeze-on consolidation can not take place when the ice sole experiences a negative thermal energy balance because ice would simply invade till pore spaces without inducing water loss in the 


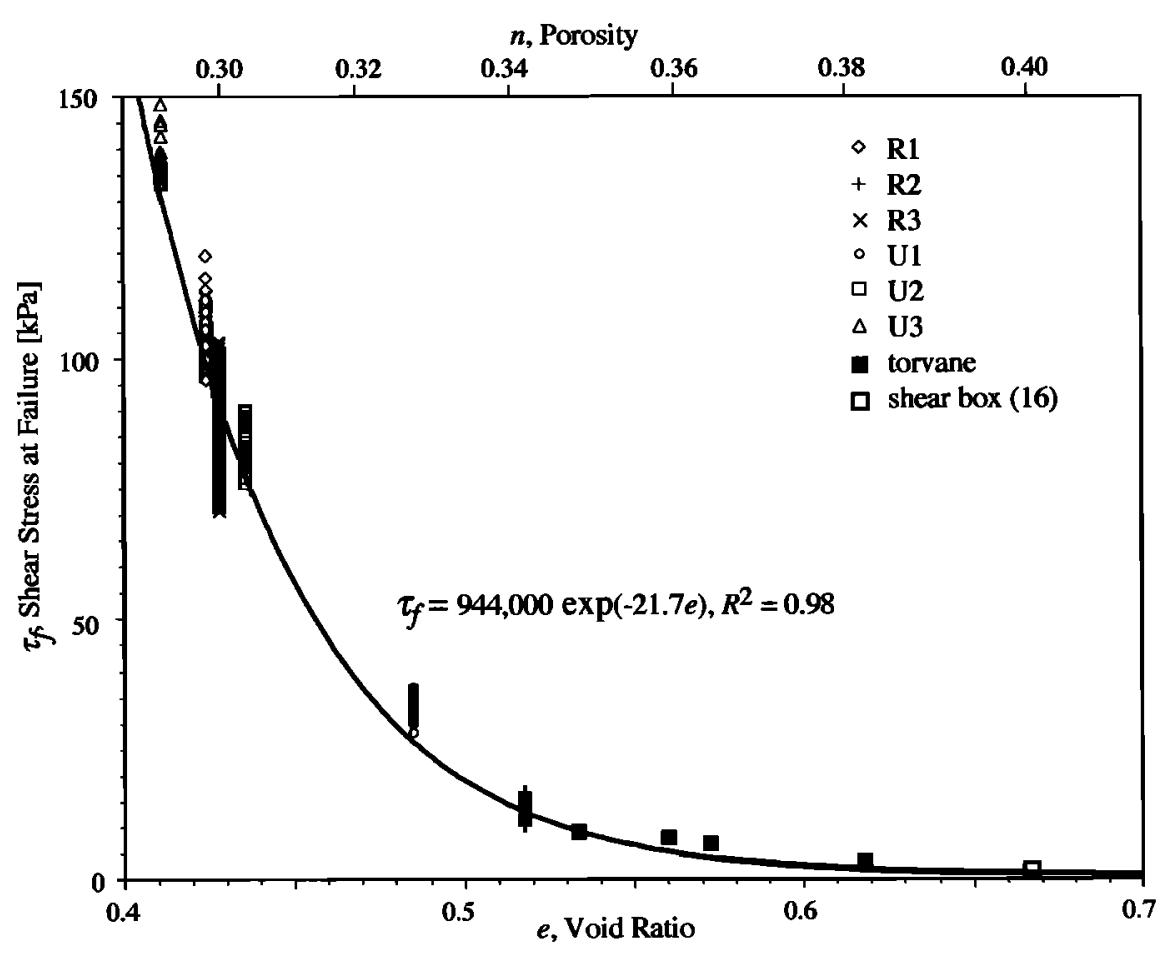

Figure 2. Empirical relationship between the strength of the UpB till $\tau_{f}$ and void ratio $e$. The thick solid line and the equation give the best fit $\tau_{f}\{e\}$ relationship derived from results of six undrained triaxial tests, R1, R2, R3, U1, $\mathrm{U} 2$, and U3 [Tulaczyk et al., this issue]. There is a reasonably close agreement between the $\tau_{r}\{e\}$ curve and data from four torvane strength tests on undisturbed samples of the UpB till (solid squares) and from 16 shear box tests (open square) $[K a m b, 1991]$ that are used as an independent check on the best fit relationship.

still unfrozen till [Iverson, 1993]. However, in the case of the fine-grained UpB till such basal accretion of till will be hindered by surface-tension effects which prevent ice from forming in or infiltrating into small pore spaces. As calculated by Tulaczyk [1999], the effective stress beneath Ice Stream B must reach at least $\sim 100 \mathrm{kPa}$ before these surface tension effects will be overcome. At this high effective stress the strength of the $U_{p B}$ till would be at least an order of magnitude greater, $\sim 45 \mathrm{kPa}$ (equation (3a) with $\tan \phi \cong 0.45$ [Tulaczyk et al., this issue]) than the observed strength of $\sim 2 \mathrm{kPa}$ [Kamb, 1991]. Herein we are inter-

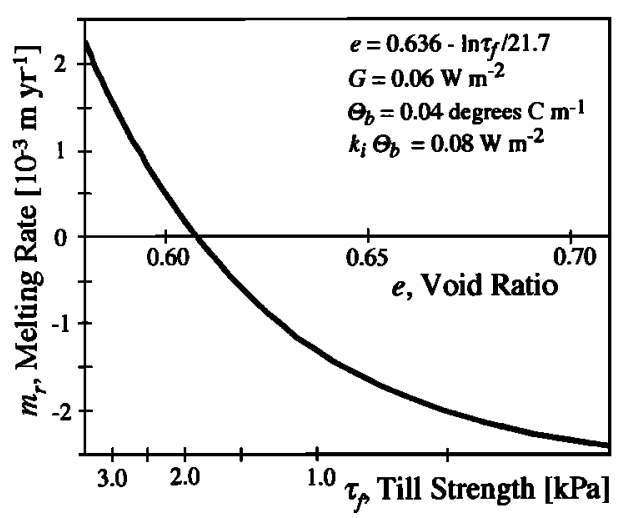

Figure 3. Sensitivity of the basal melt rate at UpB camp to void ratio and till strength (equations ( 1 ) and (3d)). (Note that limitations of the best fit $\tau_{f}\{e\}$ model are illustrated here by the fact that this model predicts that till with strength of $\sim 2 \mathrm{kPa}$ should have void ratio of $\sim 0.61$, whereas in Kamb's [1991], tests till of that strength had void ratio of $\sim 0.67$.) ested in till strength variations of only a few $\mathrm{kPa}$ away from the observed value (Figure 3), so we may safely assume that freezeon driven consolidation rather than basal accretion of till is the correct process to consider.

To verify that freeze-on driven consolidation may strengthen a several-meter-thick layer of till with a low hydraulic diffusivity $\left(c_{1} \sim 10^{-8} \mathrm{~m}^{2} \mathrm{~s}^{-1}\right.$ for the UpB till [Tulacz)k, 1998, chapter 5; Tulaczyk, 1999]), we have run finite difference models of onedimensional consolidation forced by freeze-on occurring at a constant rate of $10^{-3} \mathrm{~m} \mathrm{yr}^{-1}$ (Figure 4). The modeling results demonstrate that freeze-on driven consolidation propagates relatively unifonnly throughout a till layer several meters thick. This type of consolidation may increase the strength of a till layer by a few kilopascals within several years (Figure 4). Such a small increase in till strength is sufficient to significantly increase the basal melt rate (Figure 3). From the point of view of the physical processes considered here (equations (1), (2), and (3d)), an initial state in which basal freezing is occurring appears to be as transient as an initial state in which positive water storage is occurring $\left(m_{r}-d_{l}\right)>0$. Although the example discussed here has concentrated on the condition of basal freezing, $m_{l}<0$ and $d_{r}=0$, the results of our modeling shown in Figure 4 are equally applicable to the case of the drainage rate exceeding basal melt rate by $10^{-3}$ $\mathrm{m} \mathrm{yr}^{-1}$.

The basic result of our analysis is that the basal water-till system of an ice stream should have the tendency to drift towards a steady state in which the rate of water storage in the till is equal to the drainage rate. However, it does not mean that one can neglect the water storage term in models of sub-ice stream hydrology. This term is of fundamental importance in determining the time-dependent behavior of the subglacial system which is of 


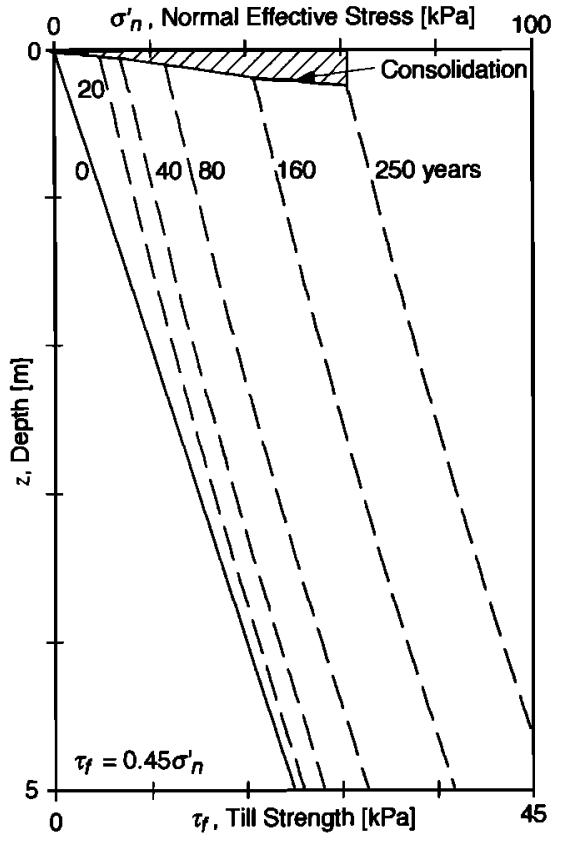

Figure 4. Consolidation of a 5-m-thick till layer driven by a constant basal ice freeze-on rate of $10^{-3} \mathrm{~m} \mathrm{yr}^{-1}$. This result is obtained by solving a one-dimensional version of the diffusion equation used to describe the process of consolidation [Scott, 1963, equation 5-43]. The till is assumed to have a hydraulic diffusivity of the UpB till, $10^{-8} \mathrm{~m}^{2} \mathrm{~s}^{-1}$ [Tulaczyk, 1998, chapter 5]. The lower boundary has a no-flow condition at $z=5 \mathrm{~m}$, and the initial distribution of the effective stress (solid line labeled 0 ) is assumed to be hydrostatic with the hydrostatic stress gradient $\rho_{\mathrm{u}} g$ equal to $10 \mathrm{kPa} \mathrm{m}^{-1}$. Dashed lines show the distribution of effective stress (top scale) and till strength (bottom scale) with depth at selected times (20,40 years and so on). The diagonally hatched area in the upper part of the diagram (labeled consolidation) gives the till thinning due to water withdrawal at the rate of $10^{-3} \mathrm{~m} \mathrm{yr}^{-1}$ through time.

interest in analysis of ice stream stability (e.g., velocity response to perturbations in till strength) and ice stream evolution.

We propose that water exchange between the basal water system and the underlying ti!! provides the main mechanism determining stability and evolution of basal hydrologic and mechanical conditions. A till layer that is several meters thick represents a non negligible reservoir of water. As an example, a 5-m-thick till with void ratio of 0.6 co contains an equivalent of $2 \mathrm{~m}$ of water. This corresponds to 2000 years of basal melting at a reasonable average rate of $1 \mathrm{~mm} \mathrm{yr}^{-1}$. Because of the codependence of till compressibility and till strength on effective stress, this significant water reservoir amounts to a "capacitance" of a hydromechanical subglacial system. Since consolidation of granular media can be approximated as a diffusion process [Scott, 1963, pp. 181-188], the characteristic timescale of this reservoir is given by $(1+e)^{2} Z_{s}^{2} / c_{1}$ and is of the order of 10 years for a system approximating the till layer beneath Ice Stream $\mathrm{B}\left(e \approx 0.7, Z_{s} \sim 1 \mathrm{~m}\right.$, $\left.c_{1} \sim 10^{-8} \mathrm{~m}^{2} \mathrm{~s}^{-1}\right)$. The hydraulic capacitance of the till layer may be neglected when short-term ice stream behavior is considered (timescales $\ll 10$ years) but must be included in realistic treatments of ice stream motion over timescales comparable to, or longer than, 10 years.

\section{Undrained Plastic Bed Model}

The analysis of sub-ice stream hydrology presented above was based on an assumption that the changes in till strength, $\Delta \tau_{f}$ of $\sim 1$ $\mathrm{kPa}$ (Figure 3), are small enough not to influence the sliding velocity of the ice stream $U_{b}$ in (1). Herein we relax this assumption and show that a similar negative feedback between meltwater production and till strength may still exist. This is possible because the relative influence of sinall till strength changes on the rate of basal melting is much greater than their influence on ice stream velocity.

Before we introduce an equation that expresses the dependence of ice stream velocity on till strength, we will further simplify our model of sub-ice stream hydrology by assuming that there is no significant long-distance drainage of meltwater fiom beneath Ice Stream B towards the grounding line. The possibility of a steady state in which drainage plays only a minor role has been considered previously by Raymond [1995] (his productionlimited conditions). This assumption of undrained conditions permits us to set the drainage rate in (2), $d_{l}$, equal to zero and to consider only the feedback between local water storage in till and the basal melt rate. In an undrained system a positive or negative basal melt rate is sustained only transiently because the changes in till void ratio driven by a non zero melt rate will force adjustments in till strength such that in a steady state the basal melt rate becomes equal to zero. The assumption of $d_{r} \equiv 0$ simplifies our model of subglacial hydrology both mathematically and conceptually but, as we will show later, it does not change significantly the most important conclusions resulting from our analysis of ice stream stability. We have stated from the beginning that the basic objective of this study is to understand the role of trll water storage in determining ice stream stability. An important point is that we can treat the feedback between water storage in till and the melting rate using observationally constrained equations $((1)$ and (3d)).

Existing observations from beneath Ice Stream B are insufficient to either prove or disprove the undrained bed model. Driven by the traditional assumption that long-distance transport of meltwater must be taking place beneath this ice stream, Enge/hardt and Kamb [1997, p. 228] have advocated the presence of a canal-type system that has been inferred theoretically by Walder and Fowler [1994]. Nonetheless, the canal model does not provide a unique explanation for any of the observations made at Ice Stream B [Engelhardt and Kamb, 1997, section 9e]. Fundamental features of the subglacial observations reported by Engelhardt and Kamb [1997] can be explained also with the assumption of undrained conditions. For instance, their measurements of slow water flow and pressure pulse propagation may be considered to be a result of borehole water injection rather than a reflection of natural behavior of the basal system. Pending collection of more data on sub-ice stream hydrology, we propose the undrained ice stream bed model not only as a convenient tool for simplifying analysis of ice stream behavior but also as a physically viable end-member of possible sub-ice stream water systems. If future observations will show that using (2) with $d_{r} \equiv 0$ or $d, \neq 0$ but independent of $e$ is too simplistic, our modeling framework can be easily modified by including a different expression for $d_{r}$.

The crucial element that is now needed to make the whole ice stream model physically self-contained is the relationship between ice stream velocity and till strength. Here we make the assumption that till strength determines basal resistance to ice stream motion, that is, till strength equals the basal shear stress $\tau_{f}$ $=\tau_{b}$. Raymond $[1996$, p. 100] has derived an equation that gives 
A
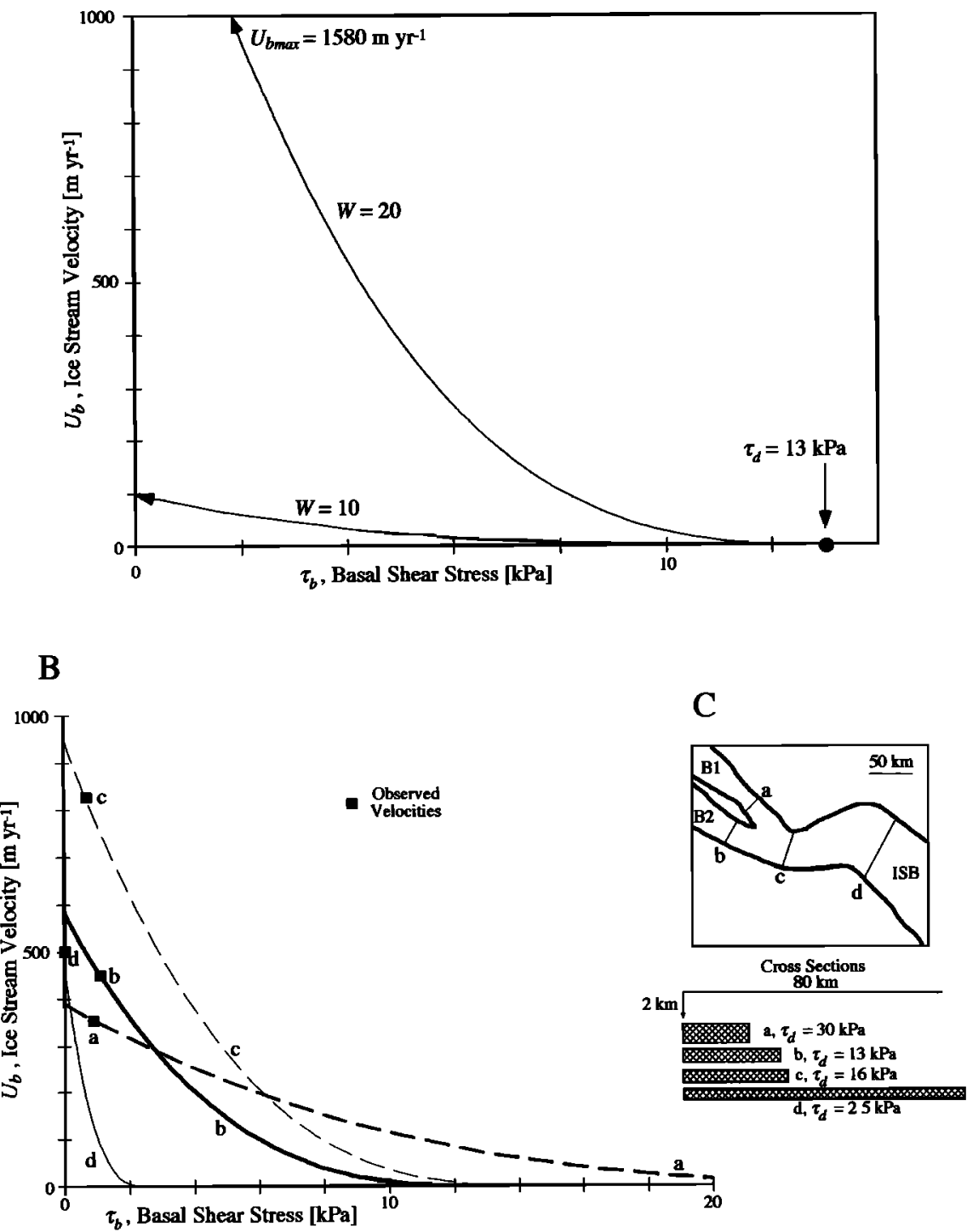

Figure 5. (a) Two examples of velocity bed strength curves calculated using (5). The nondimensional half widths $W$ of 10 and 20 ice thicknesses are representative of the range of typical values for the trunk stream of Ice Stream B. In these and all subsequent calculations, standard flow law parameters for ice at the temperature of $-15^{\circ} \mathrm{C}$ are assumed [Paterson, 1994, Table 5.2]. (b) Application of the plastic till model (equation (5)) to four selected cross sections, labeled a-d, of lce Stream B for which data on ice stream geometry and velocity are available [Bindschadler et al., 1987; Shablate et al., 1987]. Cross section b is located in the UpB area of lce Stream B. Concaveupward curves show the $U_{b}\left\{\tau_{b}\right\}$ relationships calculated from (5) and the solid squares indicate where the observed velocities fall on these curves (Note that the solid square symbols do not imply an exact knowledge of $\tau_{b}$ for each cross section; these $\tau_{b}$ values represent simply bed strengths that $(5)$ predicts from the observed ice streain velocities.) (c) Outlines of the ice stream showing locations of cross sections. Approximate width and thickness of ice in these cross sections is given by the cross-hatched rectangles in the center right (width scale $=80 \mathrm{~km}$; thickness scalc $=2 \mathrm{~km}$ ).

the centerline velocity of an ice stream moving in a rectangular channel with a homogenous till bed having everywhere velocityindependent strength $\tau_{f}=\tau_{\boldsymbol{b}}$ :

$$
U_{b}=\left(\frac{\tau_{d}-\tau_{b}}{\tau_{d}}\right)^{n} W^{n+1} U_{d}=\left(1-\frac{\tau_{d}}{\tau_{b}}\right)^{n} W^{n+1} U_{d},
$$

where $\tau_{d}=\rho_{\text {Ice }} g H \sin \alpha$ is the driving stress $\left(g=9.8 \mathrm{~m} \mathrm{~s}^{-2}\right.$ is the acceleration of gravity, $H$ is the ice thickness, and $\alpha$ is the ice surface slope), $W$ is the ice stream half width given in multiples of ice thickness, and $U_{d}=2^{1-n} \tau_{d}{ }^{\prime} H(n+1)^{-1} B_{i}^{n}$ is the calculated surface velocity for ice moving purely by internal ice deformation with basal shear stress $\tau_{b}=\tau_{d}\left(n, B_{t}\right.$, are the ice flow law constants [Raymond, 1996, equation (7)]). We consider only the centerline velocity, although in reality ice stream flow is not a perfect plug flow. However, it is a close approximation of the latter with almost all of the horizontal velocity gradients being concentrated in the narrow shear margins [see Echelmeyer et al. 1994]. Therefore we consider the cross-flow dependence of velocity a negligible effect in the context of the current, simple model of an ice stream.

Figure 5a shows an example of the dependence of ice stream velocity on the bed strength $\tau_{b}$ and the ice stream half-width $W$, 
assuming driving stress of $13 \mathrm{kPa}$ (based on ice surface slope 0.00134 measured over the lengthscale of $-35 \mathrm{~km}$ ), ice stream thickness of $1000 \mathrm{~m}$, and standard parameters for the ice flow law: $n$ equal to 3 and $2^{1-n}(n+1)^{-1} B_{1}^{n}$ equal to $1.45 \times 10^{-16} \mathrm{~s}^{-1} \mathrm{kPa}^{-3}$ for ice temperature of $-15^{\circ} \mathrm{C}$ [Engelhardt and Kamb, 1993; Paterson, 1994, p. 97]. This diagram illustrates the major features of (5) in which ice stream velocity is determined by partitioning the support of the gravitational driving stress into two components: (1) the basal shear stress and (2) the marginal shear stress which is incorporated into (5) as $\left(\tau_{d}-\tau_{b}\right)$. In this approach the weaker the bed gets the more of the gravitational stress has to be supported by ice deformation in the ice stream shear margins. This requires higher marginal shear strain rates and higher ice stream velocities [Echelmeyer et al, 1994; Jackson and Kamb, 1997; Raymond, 1996; Whillans and 'an der Veen, 1997]. The maximum ice stream veiocity for a given half width and gravitational driving stress occurs when the bed strength is equal to zero (Figure 5a). On the other hand, when bed strength is equal to the driving stress, the sliding component of ice stream velocity $U_{b}$ is equal to zero. Ice is assumed to move only by internal deformation which under the low gravitational driving stress typical for ice streams results in very slow ice surface motion, of the order of $10^{0} \mathrm{~m} \mathrm{yr}^{-1}$, much sinaller than ice streaming velocities of order $10^{2} \mathrm{~m} \mathrm{yr}^{-1}$. Theoretically, it is possible that as the till gets too strong to fail under the applied gravitational driving stress, ice velocity will be determined by ice sliding over a rigid bed of the type proposed previously for ice streams by Weertman and Birchfield [1982]. However, we consider this to be unlikely because such sliding mechanism requires lubrication by a millimeter or centimeter thick basal water film. According to the physics that we are considering here, if so much water were available in the basal system, there would be no reason for the till to consolidate and increase its strength in the first place.

To verify whether the mechanical ice stream model represented by (5) is capable of reproducing the observed velocities of Ice Stream B, we have calculated velocity versus bed strength curves for four selected cross sections of this ice stream and compared them with observed velocities (Figure 5b) [Bindschadler et al., 1987; Shabtaie et al., 1987; Whillans and van der Veen, 1993]. The observed velocities fall near the upper limits of the velocity range predicted using (5). This general agreement is especially remarkable if one considers the simplicity of (5), which has no adjustable parameters such as an enhancement factor in the ice flow law [Echelmever et al., 1994; Jackson and Kamb, 1997]. We conclude that the plastic bed model of ice stream motion expressed by (5) captures the first-order aspects of the dependence of ice stream velocity on the bed strength. In subsequent sections, we couple this plastic bed model of ice stream mechanics to the undrained bed model formulated above and analyze the properties of this coupled system (equations (1), (2), (3d), and (5)).

\section{Conditions for Ice Stream Stability}

Previously, we have shown that there is a strong coupling between water storage in till and shear heating. Under undrained conditions a sub-ice stream till bed will adjust into a steady state in which the till is weak enough so that the shear-heating term in equation (1) is small and the steady state melt rate $m_{r}$ is equal to zero (e.g., in our simulation of the UpB area $m_{r}=0$ for $\tau_{f} \approx 1.8$ $\mathrm{kPa}$; Figure 3). However, a major limitation of the calculations shown in Figure 3 was the fact that they did not include an ex- pression for ice stream velocity as a function of till strength. Inclusion of (5) permits analysis of the dependence of the basal melt rate on bed strength over the whole range of bed strengths possible beneath an active ice stream, that is, $0 \leq \tau_{b} \leq \tau_{d}$. This is done by substituting (5) for $U_{b}$ in (1):

$$
m_{r}=\frac{\tau_{b}\left(1-\tau_{b} / \tau_{d}\right)^{\prime \prime} W^{n+1} U_{d}+G-k_{i} \Theta_{b}}{L_{i} \rho_{\text {ice }}} .
$$

The new equation has two adjustable parameters, the geothermal flux $G$ and the basal ice temperature gradient $\Theta_{b}$.

In the current analysis of ice stream stability, we make the assumption that the ice stream half width $W$ and gravitational driving stress $\tau_{d}$ are both time independent. This assumption is not applicable to timescales greater than or equal to hundreds of years, but it is probably a good one for timescales shorter than this. We base this proposition on our inference that the characteristic timescale for adjustment of bed strength to a steady state value $(\sim 10$ years, equation (4)) is at least an order of magnitude shorter than the characteristic timescales for changing ice stream geometry. If widening of an ice stream requires that a weak and highly porous layer of till ( $e \sim 0.65$ for the UpB till) must be generated outside the shear margins from some preexisting more consolidated subglacial till (from (3d) $e \leq 0.55$ for the UpB till to be too strong for ice streaming, $\tau_{f} \geq \tau_{d}=13 \mathrm{kPa}$ ), then the characteristic timescale for this process is of the order of 100 years. This result can be obtained from (4) using $\Delta e \sim 0.1$ and setting the other quantities to the same reasonable values as before. Because changes in the gravitational driving stress are coupled to ice sheet mass balance, their characteristic timescale should be of order of $10^{2}$ and $10^{3}$ years [e.g., MacAyeal, 1993ab]. Based on these arguments, ice stream stability can be treated in terms of the relationship between three interrelated diagnostic parameters: $e$, $U_{b}$, and $\tau_{f}$. Therefore, we do not need to include evolution equations for $W$ and $\tau_{d}$ whose time dependence should be important only over much longer timescales. Thus we treat $W$ and $\tau_{d}$ as control parameters in our modeling. Our postulate is consistent with the recent finding that over the last four decades shear margins near the mouth of Ice Stream B have migrated outward by an equivalent of a few percent of ice stream half width but ice stream velocity in this area has actually decreased by $\sim 50 \%$ [Bindschadler and Vornberger, 1998]. Because widening should produce a velocity increase, this finding suggests that the observed velocity change was caused by a change in basal conditions.

Figure 6a illustrates the nature of the dependence of the basal melt rate on till strength, calculated using (6) with the basal temperature gradient measured at $\mathrm{UpB}, \sim 0.04^{\circ} \mathrm{C} \mathrm{m}^{-1}$ [Engelhardt and Kamb, 1993; Raymond, 1996] and three assumed values of the geothermal flux, 0.04, 0.06, and $0.08 \mathrm{~W} \mathrm{~m}^{-2}$. The shape of the $m_{r}\left\{\tau_{b}\right\}$ curves is always the same because it is always deternined by the shear heating term $\tau_{b} U_{b}$ (equation (1)). The difference between the two other thernal energy terms in (1), $G-k_{i} \Theta_{b}$, determines the vertical offset of these curves. Analysis of the shear heating function $\tau_{b} U_{b}$ shows that it reaches a maximum at the bed stiength $\tau_{b}=(n+1)^{-1} \tau_{d}$, or $\tau_{b}=0.25 \tau_{d}$ for $n=3$. To the left of this maximum, shear heating drops off because the bed strength falls towards zero and the corresponding increase in ice stream velocity is not fast enough to counteract this fall. To the right of the maximum, shear heating also drups off because the velocity decreases faster than the bed strength iricreases.

By substituting the term $\tau_{b}=(n+1)^{-1} \tau_{d}$ into (5) we can show that the magnitude of the maximum shear heating is given by

$$
\left(c_{b} U_{b}\right)_{\max }=n^{n}(n+1)^{-\mathrm{n}-1} W^{n+1} U_{d} \tau_{d}
$$




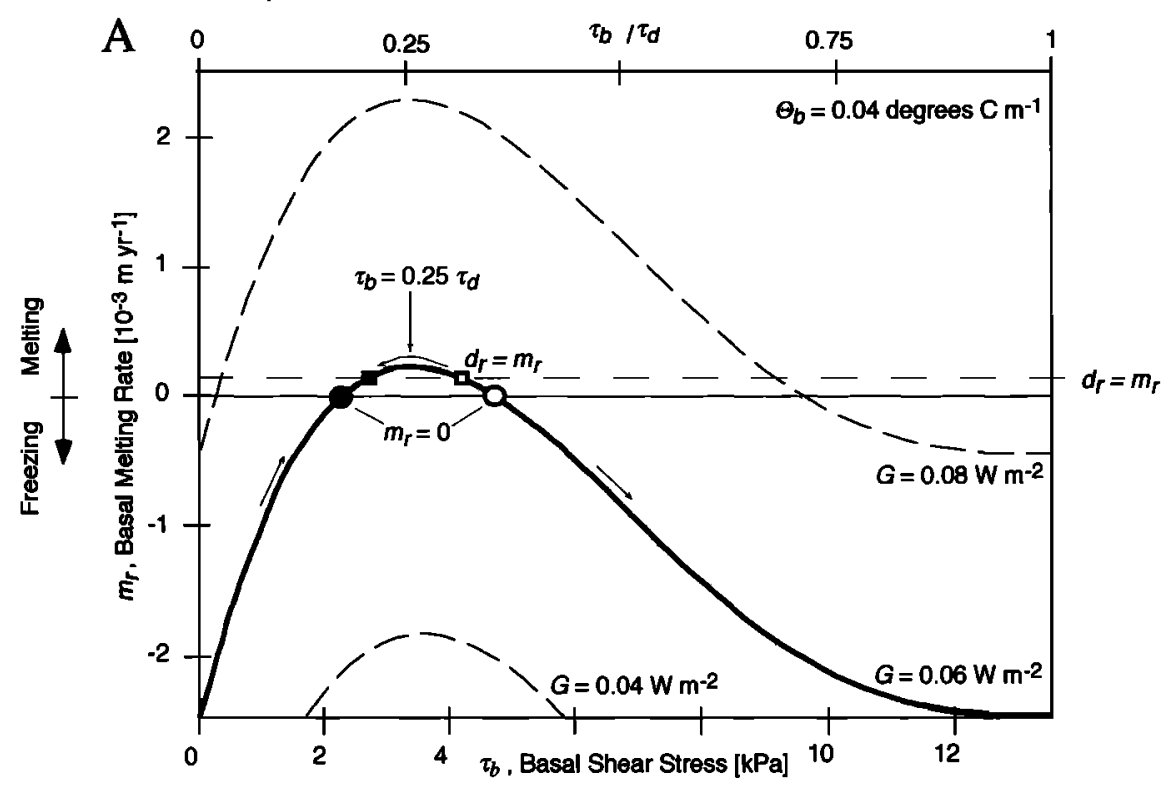

B

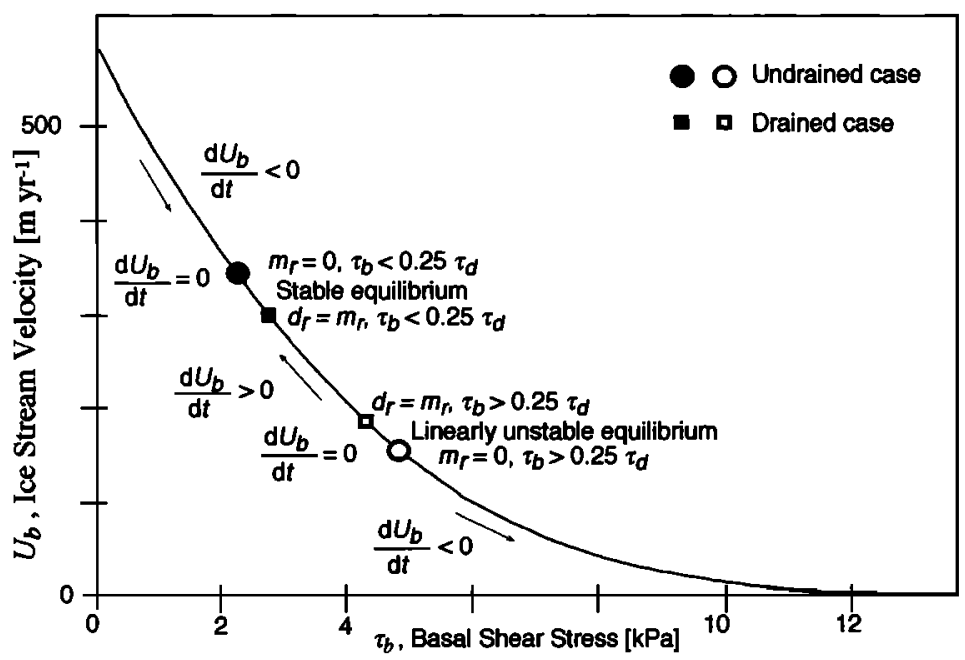

Figure 6. (a) Basal melt rate $m_{r}$ as a function of the basal strength calculated for the cross section of lce Stream B in the $U \mathrm{pB}$ area (labeled $\mathrm{b}$ in Figure $5 \mathrm{~b}$ ) (equation (6)). The open and the solid circle are plotted where the condition of basal melt rate equal to zero is met (undrained bed model). In addition, the open and the solid squares are plotted where the condition of basalt inelt rate equal to the drainage rate is met (drained bed model). (b) Ice streain velocity bed strength curve calculated from (5) for the same cross section of Ice Stream B (labeled b in Figure 5b). The open and the solid circles and squares are drawn for the same values of the bed strength $\tau_{b}$ as in Figure 6a. They indicate the stable equilibrium and the linearly unstable equilibrium of the UPB ice stream model. The arrows in Figures $6 \mathrm{a}$ and $6 \mathrm{~b}$ show the directions in which the UPB system migrates between the equilibrium states.

The fact that there is an upper bound on shear heating has an important implication because it means that the proposed condition for stable velocity of an ice strean moving over an undrained bed, namely, that $m_{1}=0$, may be met only if the following is true:

$$
G-k_{i} \Theta_{b} \geq-\left(\tau_{b} U_{b}\right)_{\max } \text {. }
$$

In addition, shear heating cannot be a negative quantity. Inspection of (1) shows that for the melt rate to be zero for at least one value of bed strength $\tau_{b}$ then:

$$
G-k, \Theta_{b} \leq 0 .
$$

Existing borehole measurements show relatively high basal temperature gradients on Ice Stream B and Ice Stream C, $\sim 0.04^{\circ}$ and
$0.05 \mathrm{C}^{\circ} \mathrm{m}^{-1}$, respectively. Such high basal temperature gradients correspond to conductive heat losses that are likely to exceed the regional geothermal flux, 0.08 and $0.1 \mathrm{~W} \mathrm{~m}^{-2}$ versus $\sim 0.06 \mathrm{~W} \mathrm{~m}^{-2}$ [Rose, 1979]. These values suggest that inequality (9) is fulfilled for the West Antarctic ice streams.

Let us now concentrate on the case in which the two thermal conditions, equations (8) and (9), are fulfilled. With the exception of the case $\left(\tau_{b} U_{b}\right)_{\max }+G-k_{i} \Theta_{b}=0$, there will always be two values of the bed strength for which the basal melt rate is zero (Figure 6a). This result raises the question whether there are two stable equilibrium states in our undrained plastic bed model. Simple inspection of Figure 6 suggests that only one of these equilibria is truly stable (solid circle) with the other one being 
linearly unstable (open circle). These two equilibria occur on either side of the bed strength magnitude, $\tau_{b}=(n+1)^{-1} \tau_{d}=0.25 \tau_{d}$, for which shear heating is maximum (equation (7)). Around the stable equilibrium, $m_{1}=0$ and $\tau_{-}<0.25 \tau_{d}$, the undrained plastic bed (UPB) system exhibits a negative feedback which brings the bed conditions back to the steady state (arrows in Figure 6). However, around the linearly unstable equilibrium, $m,=0$ and $\tau_{\text {: }}$ $>0.25 \tau_{d}$, there is positive feedback which will reinforce small perturbations, pushing the UPB system either toward the stable equilibrium or completely out of the range of the weak-bed state $\left(\tau_{l}<\tau_{d}\right)$ for which ice streaming occurs (equation (5)). This conclusion does not change if one permits some constant non zero drainage rate $d_{1}$. In this case, the two equilibria occur at $d,=m$, (solid square and open square in Figure 6).

This important result may be obtained in a mathematically more rigorous way by performing linear stability analysis on the UPB system of (1), (2), (3d), and (5). We can substitute (6) for $m$, in (2) and set $\tau_{b}=\tau_{f}=a \exp (-b e)$ (equation (3d)) thus

$$
\dot{e}=\frac{a \exp (-b e)\left(1-{ }^{a \exp (-b e) / \tau_{d}}\right)^{\prime \prime} W^{n+1} U_{d}+G-k_{l} \Theta_{b}}{Z_{s} L_{l} \rho_{1 c e}}-\frac{d_{1}}{Z_{s}}
$$

where the last term represents the influence of the drainage rate on changes of till void ratio (equation (2)). It is retained here to demonstrate that the results of our stability analysis do not depend on the assumption of undrained conditions. By differentiating $(10)$ with respect to void ratio we obtain:

$$
\frac{\partial e}{\partial e}=(b \xi)\left(1-\frac{\xi}{\tau_{d}}\right)^{n}\left\{\frac{n \varepsilon\left[1-\xi / \tau_{d}\right]^{-1}}{\tau_{d}}-1\right]\left(\frac{w^{n+1} U_{d}}{Z_{s} L_{i} \rho_{i c e}}\right),
$$

where for clarity of presentation we use the dummy variable $\xi=$ $a \exp (-b \epsilon)$. Note that the drainage rate drops out of the analysis as long as it is not a function of void ratio. Taking advantage again of the fact that there is one-to-one correspondence between till strength and till void ratio, $\tau_{f}=a \exp (-b e)=\xi,(11)$ can be simplitied to

$$
\frac{\partial \dot{e}}{\partial e}=\left[(n+1) \frac{\tau_{f}}{\tau_{d}}-1\right] b \tau_{f}\left(1-\frac{\tau_{f}}{\tau_{d}}\right)^{n-1}\left(\frac{W^{n+1} U_{d}}{Z_{s} L_{t} \rho_{c c e}}\right) .
$$

Because all other terms are always positive, it is only the term [ $(n$ $\left.+1) \tau_{f} / \tau_{d}-1\right]$ that determines the sign of this differential equation. Saddle-node bifurcation occurs when

$$
(n+I) \tau_{f} \tau_{d}-l=0 \quad \tau_{f}=(n+I)^{-1} \tau_{d} .
$$

Taking the commonly used value of the flow law exponent $n=3$ [Paterson, 1994, p. 94], this condition becomes $\tau_{f}<0.25 \tau_{d}$. For $\tau_{f}<(n+1)^{-1} \tau_{d}$ the derivative $\hat{o} \dot{e} / \hat{\partial} e$ is less than zero and perturbations away from the value of $e$ making $m_{r}=0$ decay with time. This is a sufficient condition for a stable equilibrium (solid circle, Figure $6 \mathrm{~b})$. In the opposite case, $\tau_{f}>(n+1)^{-1} \tau_{d}$ and $\partial \dot{e} / \hat{\partial} e>0$, perturbations grow with time leading to a linearly unstable equilibrium at the greater values of $e$ and $\tau_{f}$ that make $m_{r}=0$ (open circle, Figure $6 \mathrm{~b}$ ). This positive feedback will force the UPB system to migrate either toward the stable equilibrium or completely out of the range of the weak-bed state $\left(\tau_{b}<\tau_{d}\right)$ for which ice streaming occurs (equation (5)).

The physical significance of the stability condition (equation (13)) is quite striking because this condition shows that a steady state ice stream should have a very porous and weak till bed. Observations from drilling at the UpB camp on Ice Stream B are consistent with this stability condition $\left(e \approx 0.6\right.$ to 0.9 and $\tau_{f}=2 \pm$ $0.5 \mathrm{kPa}[K a m b, 1991 ;$ Tulaczy'k, 1998]). Thus the physics of the
UPB model of ice stream motion agrees well with the observational constraints available for Ice Stream B.

It is important to note that in the UPB system of equations there is a one-to-one correspondence between $e, \tau /$, and $U_{b}$. Therefore this scalar dynamical system may be regarded as an evolution in either of these diagnostic variables. Previously, we have argued that the physics of the UPB model couples these three variables in a system with a relatively short characteristic timescale of $\sim 10$ years (equation (4)). We postulated also that the gravitational driving stress $\tau_{d}$ and the half-width of an ice stream $W$ can be treated as control parameters because they change much more slowly. Equation (13) gives the condition for the saddle node bifurcation in terms of $\tau_{f}\left\{\tau_{d}\right\}$ but the same condition may be also expressed in terms of $e\left\{\tau_{d}\right\}$ and $U_{b}\left\{\tau_{d}, W\right\}$ (equations (3d), (5), and (13)):

$$
\begin{gathered}
e=-\ln \left[\tau_{d} / a(n+1)\right] / b \\
U_{b}=\left(\frac{n}{n+1}\right)^{\prime} W^{n+1} U_{d}=\left(\frac{n}{n+1}\right)^{\prime} W^{n+1} \tau_{d}^{n}\left(\frac{2^{1-n} B_{t}^{n} H}{n+1}\right)
\end{gathered}
$$

Figure 7 plots the threshold values of all three diagnostic variables (equations (13), (14a), and (14b)) as functions of the two control parameters $\tau_{d}$ and $W$. Perhaps the most interesting result of these calculations is shown in Figure $7 \mathrm{a}$ which demonstrates that the requirement of a steady state porous bed applies to a wide tange of relevant values of $\tau_{d t}$ (void ratio, $e>0.53$, porosity greater than $\sim 0.35$ for $\tau_{i f}=0$ to $30 \mathrm{kPa}$ [Bentley, 1987]). Such waier-rich till will asso be weak, $\tau_{f}-\hat{v}$ to $7.25 \mathrm{kPa}$ (Figure $7 \mathrm{~b}$ ). Because of the sensitive dependence of ace stream velocity $U_{b}$ on $i_{d}$ and $W$, interpretation of stabiiity of the LPB system in terms of this diagnostic variable is more complex (Figure 7c).

Heretofore, our discussion has focused on the conditions for a stable ice stream mode in the UPB system. However, inspection of the UPB equations (1), (2), (3d), and (5) shows that in addition to the active, ice stream mode, this model has a second statle mode, in which the ice base is undergoing freeze-on $\left(m_{1}<0\right)$, the strength of the till bed is greater than the driving stress, and ice moves slowly by internal deformation alone. We call this the ice sheet mode.

Strictly speakıng, both of these modes can be included explicitly into the UPB model by modifying the ice-flow equation (5) to include not only the basal vel scity component $\left(U_{b}\right)$ but also the velocity component due to inte.:ial ice defornation $\left(U_{\text {def }}\right)$ :

$$
U_{s}=U_{b}+U_{d e t}=\left[\left(1-\frac{\tau_{b}}{\tau_{d}}\right)^{\prime \prime} W^{n+1}+\left(\frac{\tau_{b}}{\tau_{d}}\right)^{n}\right] U_{d}
$$

where $U_{s}$ is the ice surface velocity and all the other symbols have been previously explained (see equation (5)). However, the sliding component $U_{b}$ (when $W$ is typically $\sim 10$ ) is significantly greater than the deformational component $U_{\text {det }}$ for all values of $\tau_{b}$ but the ones very near $\tau_{d}\left(\tau_{b} \approx 0.99 \tau_{d}\right)$. Thus the modification shown in (15) does not change significantly the physics of the UPB model. Basal states between the ice stream and ice sheet modes can be achieved only transiently when the system migrates from one of the two steady states to the other. Within the physical framework of the UPB model such switches between the two modes may be achieved by changing the basal conductive heat loss $\left(k_{1} \Theta_{b}\right)$. This may force the $m,\left\{\tau_{b}\right\}$ curve (e.g., Figure 6a) to move completely below or above the line $m_{r}=0$. If the $m_{,}\left\{\tau_{b}\right\}$ curve for an active ice stream migrates completely below this line, basal freeze-on occurs for all admissible combinations of $\tau_{b}$ and $U_{b}$, and the ice stream mode will be replaced by the ice sheet mode If the system is in the ice sheet Inode and the $m_{1}\left\{\tau_{b}\right\}$ curve 
migrates above the $m_{r}=0$ line, basal melting will begin and the system will gradually switch to the ice stream mode.

The two modes inferred from the physics of the UPB model correspond well to the previous glaciological inferences made in West Antarctica where fast ice stream motion $\left(\sim 100 \mathrm{~m} \mathrm{yr}^{-1}\right)$ over a presumably weak till bed occurs adjacent to slow ice-sheet mo-

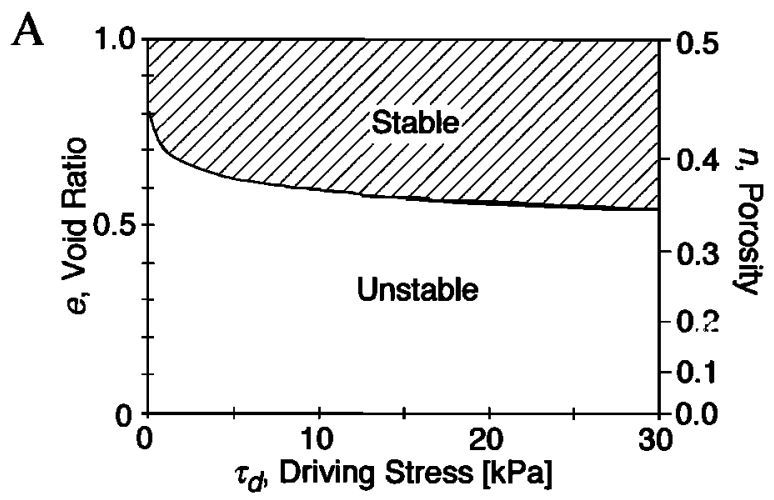

B
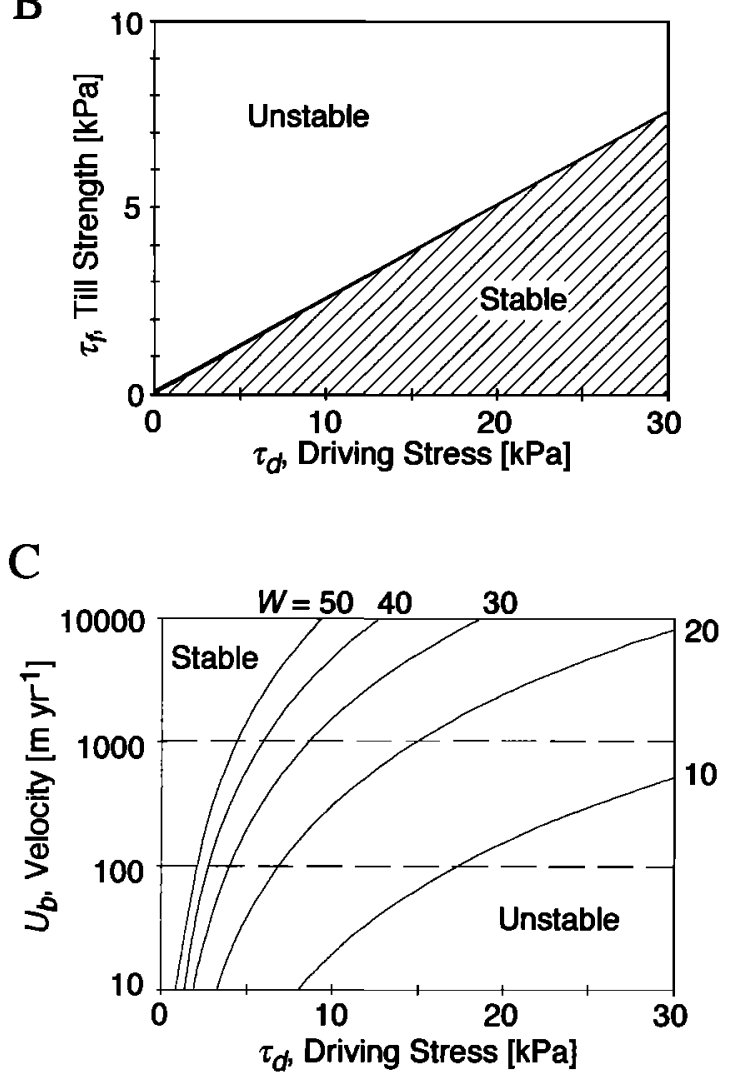

Figure 7. Conditions for the saddlc node bifurcation expressed in terms of the three diagnostic variables: (a) void ratio $e$, (D) till strength $\tau_{f}$, and $(C)$ ice stream velocity $U_{b}$, given as functions of the two control variables, driving stress $\tau_{d}$ (equations (13), (14a), and (14b)) and ice stream half width expressed in multiples of ice thickness $W$. The latter appears only in Figure $7 \mathrm{c}$. Values of the driving stress $(030 \mathrm{kPa})$ and of the half-width (10-50) are representative for the West Antarctic ice streams [Bentley, 1987; Shabtaie et al., 1987]. Diagonal hatching in Figures $7 \mathrm{a}$ and $7 \mathrm{~b}$ marks the fields in which steady state of an ice stream is possible. In Figure $7 \mathrm{c}$, stable states are possible to the left of each of the five curves drawn for different values of $W$. tion $\left(\sim 1 \mathrm{~m} \mathrm{yr}^{-1}\right)$ over a presumably strong bed. Our model offers a physical explanation for why such a pattern of contrasting basal conditions and contrasting ice velocities may develop if an ice sheet has some initial variations in spatial distribution of the basal thermal energy balance.

A third stable mode can be inferred from the UPB model. This mode arises when the condition specified by inequality (9) is relaxed. As mentioned before, if the geothermal flux is greater than the conductive heat loss, then the basal thermal energy balance is always positive because shear heating is a positive quantity. Therefore only $m_{r}>0$ is possible under these conditions. When $m$, is always positive, till weakening driven by $m_{r}>0$ will inevitably move the UPB system towards an extremely water-rich till whose strength will be zero (equations (2) and (3d)). Such till is possible only when the subglacial effective stress is zero, so the ice weight is borne entirely by the pore pressure. This situation is likely to be associated with ice bed separation and formation of a distributed basal drallagc system, such as a water film or water pockets [Alley et al., 1089; Hooke and Pohjola, 1994]. With bed strength equal to zero, the ice stream velocity will take on the maximum value given by (5) for $\tau_{b}=0$. This stable mode can be called an "ice shelf like" mode because of the condition $\tau_{b}=0$ and because of the inference that the ice in this mode woulc be practically afloat [Paterson, 1994, pp. 290-301]. As we have suggested in the statement following inequality (9), this cond tion does not seem to be fulfilled in the two localities on Ice Strecm B and Ice Stream $C$ where measurements of the basal temperature gradient were made [e.g., Engelhardt and Kamb, 1993]. However, circumstances under which this condition could be true cannot be excluded.

From an ice stream dynamics point of view, there is a relatively small difference between this ice shelf-like mode, $\tau_{b}=0$, arid the ice stream mode, $0<\tau_{b}=--<0.25 \tau_{d}$, because in both cases the velocities of ice motion prodicted by (5) are similarly high. For example, for $n=3$ the steady state velocity in the ice stream mode is between $42 \%$ and $100 \%$ of the velocity in the ice shelf-like mode. Pending inew data which could verify whether the condition $G-k_{t} \Theta_{b}>0$ is realistic for the West Antarctic ice streams, we propose that the steady state of these ice streams corresponds to the ice-stream mode of the UPB model.

\section{Conclusions}

The fact that the water content and the strength of the UpB till are both sensitively dependent on effective stress suggests a need for a new model of sub-ice stream hydrology that includes (1) water storage in till pore spaces and (2) the dependence of melt rate on elfective stress through the dependence of shear heating on the till strength. Such an hydrologic model exhibits a strong negative feedback effect between water storage in till and till strength. Due to this negative feedback, till water content, till strength, and shear heating adjust to steady state values such that the basal melt rate is equal to the drainage rate (in a drained bed model) or to zero (in an undrained bed model). The undrained bed model, which is favored by us, was coupled with an expression for the velocity of an ice strean moving over a till bed of plastic rheology to obtain a physically self-consistent ice stream model, the undrained plastic bed (UPB) model. Inclusion of a void ratio-independent drainage term would not change significantly any of the results of our analysis of ice stream behavior. In the UPB model, ice stream velocity is controlled directly by ice deformation in the shear margins and the till strength determines 
the partitioning of the driving stress between the bed and the margins. Stability analysis performed on the UPB model reveals two stable modes: (1) an ice stream mode in which the basal melt rate is equal to zero, the bed strength is much smaller than the driving stress, and ice velocities are high; and (2) an ice sheet mode in which the melt rate is less than zero, bed strength is greater than the driving stress, and basal sliding velocity is zero. The UPB model suggests also that evolution of an ice stream may be controlled by the evolution of the basal thermal regimen. For instance, ice stream stoppage is possible when the basal conductive heat loss exceeds the heat supplied by a combination of the geothernal flux and the inaximum shear heating. In this situation, the stability condition $m_{1}=0$ cannot be fuliilled for any bed strength and the positive feedback between basal rreezing and bed strength wiil force the ice stream system to nigrate toward the second stable mode, the ice sheet mode. The transition in the opposite direction, from the ice sheet mode to the ice stream! mode, is also a run away process which takes over as soon as the bed strength equals the driving stress, $\tau_{v}=\tau_{d}$, and the basal melt rate exceeds zero. This result demonstrates that small perturbation in the basal thennal energy balance may trigger major rearrangements in an ice stream system.

Acknowledgments. We acknowledge financial support provided for this research from the National Science Foundation through two grants (OPP-9219279 and OPP-9319018) to B.K. and H E. Additional support to S.T was provided by the Henry and Grazyna Bauer Fellowshıp. Insightful reviews from Garry Clarke, Roger Hooke, Charlie Raymond, and Joseph Walder have helped us improve this paper

\section{References}

Alley, R.B., Defonming-bed origin for southern Laurentide till sheets, $J$ Glaciol., 37, 67-76, 1991.

Alley, R.B., and D.R. MacAyeal, Ice-rafted debris associated with binge purge oscillations of the Laurentide Ice Sheet: Paleoceanography, 9, 503-511, 1994.

Alley, R.B., D.D. Blankenship, C.R. Bentley, and S.T. Rooney, Deformation of till beneath Ice Stream B, West Antarctica, Nature, 322, 57-59, 1986

Alley, R.B., D.D. Blankenship, S T. Rooney, and C R. Bentley, Till beneath Ice Streain B, 3, T1ll deformation: Evidence and implications, $J$. Geophys. Res., 92, 8921-8929, 1987a.

Alley, R. B.. D.D Blankenship. S.T. Rooney, and C.R. Bentley, Till beneath Ice Stream B, 4, A coupled ice-till flow model, J. Geophys. Res, 92, 8931-8940, 1987b.

Alley, R.B., D.D. Blankenship, S.T. Rooney, and C.R. Bentley, Waterpressure coupling of sliding and bed deformation 3. Application to Ice Stream B. Antarctica, J. Glaciol., 35, 130-139, 1989.

Anandakrishnan, S., and C.R. Bentley, Micro-earthquakes beneath Ice Streain B and Ice Stream C, West Antarctica, J Glaciol., 39, 455462, 1993

Bentley, C.R., Antarctic ice streams: $\Lambda$ review, J. Geophys. Res, 92, 8843-8858, 1987.

Bentley, C.R., Rapid sea-level rise soon from West Antarctic Ice Sheet collapse, Science, 275, 1077-1078, 1997.

Bindschadler, R., West Antarctic Ice Sheet collapse, Science, 276, 242$246,1997$.

Bindschadler, $R$, and $P$. Vormberger, Changes in the West Antarctic lce Sheet since 1963 from declassified satellite photography, Science, 279, 669-671, 1998.

Bindschadler, R, S N Stephenson, D.R. MacAyeal, and S. Shabtate, Ice dynamics at the mouth of Ice Stream B, Antarctica, J. Geophy's. Res., 92, 8885-8894, 1987.

Blankenship, D.D., C R Bentley, S.T. Rooney, and R B. Alley, Seismic measurements reveal a saturated porous layer beneath an active Antarctic rce stream, Nature, 322, 54-57, 1986.
Blankenship, D D., C.R. Bentley, S T. Rooney, and R.B, Alley, Tıll beneath Ice Stream B, I, Properties denved from seisinic travel times, J. Geophys. Res., 92, 8903-8911, 1987

Boulton, G S , Theory of glacial erosion, transport and deposition as a consequence of subglacial sedıment defornation, J. Glaciol, 42, 4362,1996

Clark, PU, Surface form of the southern Laurentide Ice Sheet and its implications to ice sheet dynamics, Geol. Soc Am Bull, 104, 595605,1992

Clark, P.U., and J S Walder, Subglacial drainage, eskers, and deforming beds beneath the Laurentide and Eurasian ice sheets, Geol Soc Am. Bull, , I06, 304-314, 1994

Clarke, G K C , Subglacial till: A physical framework for its propertıes and processes, J. Gecphys Res., 92, 9023-9037, 1987

Echelmeyer, K.A., W.D. Hamson, C Larsen, and J.E. Mitchell, The role of the margins in the dynamics of an active ice stream, J. Glactol., $40,527-538,1994$.

Engelhardt, $\mathrm{H} \mathrm{F}$, and B. Kamb, Vertical temperature profile of ice stream B, Antarct. J U S., 28,63-66, 1993.

Engelhardı, H., and B. Kaınb, Basal hydraulic system of a West Antarctıc ice stream Constrans from borehole observations, J. Glaciol., 43, 207-230, 1997.

Engelhardt, H, and B. Kamb, Sliding velocity of Ice Stream B, J. Gilaciol., 44, 223-230, 1998

Engelhardt, H., N. Humphrey, B. Kamb, and M. Fahnestock, Physical conditions at the base of a fast moving Antarctic ice stream, Science, 248, 57-59, 1990.

Hooke, R.L., and V.A. Pohyola, Hydrology of a segment of a glacier situated in an overdeepening. Storglaciaren, Sweden, J. Glaciol., 40 , 140-148, 1994.

Hughes, T., Can ice sheets trigger abrupt climatic change?, Arct. Alp. Res., 28, 448-465, 1996.

Iverson, N.R., Regelation of ice through debris at glacier beds: Implications for sediment transport, Geology, 2/, 559-562, 1993.

Jackson, M., and B. Kamb, The marginal shear stress of Ice Stream B, West Antarctica.J Glactol., 43, 415-426, 1997.

Kamb, B., Rheological nonlınearity and flow instability in the deformingbed mechanism of ice stream motion, $J$. Geophys Res, 96, 16,585. $16,595,1991$.

Kamb, B., and H.F. Engelhardt, Antarctic ice stream B: Conditions controlling its motion and interactions with the clinate system, IAHS Publ., 208, 145-154, 1991.

Lingle, C.S., and T.J. Brown, A subglacial aquifer bed model and water pressure dependent basal sliding relationship for a West Antarctic ice stream, in Dinamics of the West Antarctic lce Sheet, edited by C.J van der Veen and J. Oerlemans, pp. 249-285, D. Reidel, Norwell, Mass., 1987.

MacAyeal, D.R., Irregular oscillations of the West Antarctic Ice Sheet, Nature, 359, 29-32, 1992.

MacAyeal, D.R., A low-order model of the Heinnch event cycle, Paleoceanography, 8, 767-773, 1993a.

MacAyeal, D.R., Binge-purge oscillations of the Laurentide ice sheet as a cause of the North-Atlantic Heinrich events: Paleoceanography, 8 , 775-784, 1993b.

Marshall, S.J., G.K.C. Clarke, A S Dyke, and D.A. Fisher, Geologic and topographic controls on fast-flow in the Laurentide and Cordilleran ice sheets: J. Geophys. Res., 101, 17,827.17,839, 1996.

Paterson, W.S.B., The Physics of Glaciers, 3rd ed., Pergamon, Tanytown, N.Y, 1994.

Raymond, C, Constraints on the velocity of ice streans imposed by their widths, Eos Trans AGU, 76, 209, 1995.

Raymond, C., Shear margins in glaciers and ice sheets, J. Glaciol., 42, 90-102, 1996

Rose, K.E., Characteristics of ice flow in Mane Byrd Land, Antarctica, $J$. Glaciol., 24, 63-75, 1979.

Schofield, A.N., and C.P. Wroth, Critical State Soil Mechanics, McGraw-Hill, New York, 1968.

Scott, R.F., Principles of Soil Mechanics, Addison-Wesley-Longman, Reading, Mass., 1963.

Shabtare, S., I.M. Whillans, and C.R. Bentley, The morphology of ice streams A, B, and C, West Antarctica, and their environs, J. Geophys. Res , 92, 8865-8883, 1987.

Tulaczyk, S., Basal mechanics and geologic record of ice streaming, West Antarctica, Ph.D. thesis, 37 l pp.. Calif. Inst. of Technol, Pasadena, 1998 
Tulaczyk, S, Ice sliding over weak, fine-grained tills: Dependence of icetill interactions on till granulometry, in Glacial Processes, Past and Modern, edited by D.M. Mickelson and J. Attig, Spec. Pap. Geol. Soc. Am., 537, 159-177, 1999.

Tulaczyk, S., B. Kamb, R.P. Scherer, and H.F. Engelhardt, Sedimentary processes beneath a West Antarctıc ice stream; constraints from textural and compositional properties of subglacial debris, $J$ Sediment. Res., 68, 48\%-496, 1998.

Tulaczyk, S., W.S Kamb, and H.F. Engelhardt, Basal mechanics of Ice Stream B, Wes: Antarctica, 1, Till mechanics, J. Geophys. Res., this issue.

Surcotte, D.L., and G. Schubert, Geodynumics Applications of Contunuum Physics to Geological Problems, Jokn Wiley, Neu' York, i 982

van der Veen, C.J., and I.M. Whillans, Model expenmenis on the evolution and stability of ice streams, Ann. Glaciol., 23, 129-137, 1496.

'valder, J.S., and A. Fowler, Channelized subglacial drainage over a deformable bed, J. Glaciol., 40, 3-15, 1994.

Weertman, J, and G.E. Birchfield, Subglacial water tlow under ics streams and West Antarctic ice-sheet stability, Ann. Glaciol., 3, 316320,1982

W'hillans, I.M., and C.J. van der Veen, New and improved determınations of velocity of Ice Stream B and Ice Stream C, J. Glaciol., 39, 483-490 1993.

Whillans, I.M., and C J. van der Veen, The role of lateral drag in the dynamics of Ice Stream B, Antarctica: J Glactol., 43, 231-237, 1997.

H.F. Engelhardt and W.B. Kamb, Division of Geological and Planetary Scıences, California Instıtute of Technology, Pasadena, CA 91125. (hermann@gps.caltech.edu, barclay@gps.caltech.edu )

S. Tulaczyk, Department of Geological Sciences, University of kientucky, 101 Slone Bldg., Lexington, KY 40506. (smtula0@pop.uky.edu.)

(Received August 6, 1998; revised September 1. 1999; accepted September 13, 1999.) 